\title{
Design and simulation of Dynamic Voltage Restorer (DVR) supported by solar panels
}

\section{Diseño y simulación de un Restaurador Dinámico de Voltaje (DVR) soportado por paneles solares}

\author{
ANTONIO-LARA, Omarì, GARCÍA-VITE, Pedro Martín*, CASTILLO-GUTIÉRREZ, Rafael and \\ CISNEROS-VILLEGAS, Hermenegildo
}

TECNM / Instituto Tecnológico de Ciudad Madero, División de estudios de posgrado e investigación

ID $1^{\text {st }}$ Author: Omar, Antonio-Lara / ORC ID: 0000-0002-5146-4820, CVU CONACYT ID: 1036314

ID $1^{\text {st }}$ Co-author: Pedro Martín, García-Vite / ORC ID: 0000-0001-6019-7958, CVU CONACYT ID: 227310

ID $2^{\text {nd }}$ Co-author: Rafael, Castillo-Gutiérrez / ORC ID: 0000-0001-8599-892X, CVU CONACYT ID: 63299

ID $3^{\text {rd }}$ Co-author: Hermenegildo, Cisneros-Villegas / ORC ID: 0000-0001-7601-0449, CVU CONACYT ID: 63302

DOI: $10.35429 / J R D .2021 .19 .7 .31 .36$

Received March 17, 2021; Accepted June 30, 2021

\begin{abstract}
This work presents the design and simulation of a Dynamic Voltage Restorer (DVR) to mitigate power quality problems such as voltage sags and swells at sensitive loads to these types of disturbances, but with a compensation topology using one the most popular of the renewable energies, currently employed, which is photovoltaic solar energy. The DVR must operate with a control loop, monitoring the voltage at the load side and generating the voltage for compensation during the disturbances. The energy is obtained, from an array of solar panels for the injection of active power. The control algorithm discussed in this article is based on the Clark and Park transformations to generate the required signals for voltage compensation, these mathematical techniques allow fixing the variables and hence simplicity for the controller design. The results of the simulation in MATLAB/Simulink are used to show the performance of the proposed topology with symmetrical voltage sags in the distribution system.
\end{abstract}

Power quality, Solar energy, Voltage sag

\begin{abstract}
Resumen
En este trabajo se presenta el diseño y simulación de un Restaurador Dinámico de Voltaje (DVR) para mitigar problemas de la calidad de la energía como huecos y elevaciones de tensión en cargas sensibles a este tipo de perturbaciones, pero con una topología de compensación utilizando una de las energías renovables con mayor auge actualmente, que es la energía solar fotovoltaica. El DVR debe operar con un lazo de control, monitoreando el voltaje en la carga y generando el voltaje de compensación durante el disturbio. La energía para la compensación, es obtenida de un arreglo de paneles solares para la inyección de potencia activa. El algoritmo de control discutido en este artículo se basa en las transformaciones de Clark y Park para generar las señales requeridas para la compensación de voltaje, estas herramientas matemáticas permiten fijar las variables y con ello simplicidad para el diseño del controlador. Los resultados de la simulación en MATLAB/Simulink son usados para mostrar el desempeño de la topología propuesta ante huecos de tensión simétricos en el sistema de distribución.
\end{abstract}

Calidad de la energía, Energía solar, Hueco de tensión

Citation: ANTONIO-LARA, Omar, GARCÍA-VITE, Pedro Martín, CASTILLO-GUTIÉRREZ, Rafael and CISNEROSVILLEGAS, Hermenegildo. Design and simulation of Dynamic Voltage Restorer (DVR) supported by solar panels. Journal of Research and Development. 2021. 7-19: 31-36

\footnotetext{
* Correspondence to Author (e-mail: pedro.gv@cdmadero.tecnm.mx)

$\dagger$ Researcher contributing as first author.
} 


\section{Introduction}

In recent years, industrial companies, as well as residential and commercial users have focused their attention on the problem of power supply quality and demand better conditions in the quality of the voltage wave, because a poor quality of supply brings considerable economic losses. Currently, the electrical distribution system has loads that are more sensitive to disturbances such as: voltage interruptions, voltage rises and dips, as a consequence of the connection and disconnection of large motors, connection of photovoltaic systems to the grid, capacitor banks, short-duration interruptions, among others.

Under these circumstances, FACTS devices used in transmission systems to improve power quality have been taken as a basis and new power conditioning devices for the distribution system (D-FACTS) have been designed to regulate and control the power flow. Such is the case of the Dynamic Voltage Restorer (DVR) which is a D-FACTS technology that is connected in series with the distribution line, being able to inject a compensation voltage with the purpose of improving the voltage quality in a sensitive load in case of system disturbances.

On the other hand, renewable energy sources are increasingly incorporated in applications where fossil fuels and their derivatives were used, since they do not produce environmental pollution and, in addition, some such as solar photovoltaic has an almost inexhaustible source to produce electricity. This paper presents an application of this renewable source, using solar panels to supply energy to the DVR and give greater depth of compensation by injecting active power.

This paper is divided into the following concepts: Section II presents in a general way the structure of the DVR supported by solar panels, and its operation. Section III discusses the control strategy proposed in this paper. Finally, Section IV presents the simulation results in MATLAB/SIMULINK to validate the proposed DVR topology to mitigate voltage dips.

\section{General description of the system}

The DVR is a power conditioner that is connected in series with the load through a threephase injection transformer, connected in star primary and open secondary.
Its purpose is to mitigate dips and voltage rises that affect the sensitive load. Figure 1 shows that a test load is considered large enough to cause a voltage drop at the common coupling point (CCP), this load is controlled by switch SWI to simulate a disturbance in the system. A solar panel array is also connected to supply voltage at the inverter DC link voltage, but upstream of the inverter a Boost type DC-DC power converter is connected to boost the voltage generated by the panel to levels acceptable to the inverter. In addition, a passive filter is required at the inverter output to remove unwanted components in the output voltage produced by the high switching speed of the semiconductor devices that make up the inverter.

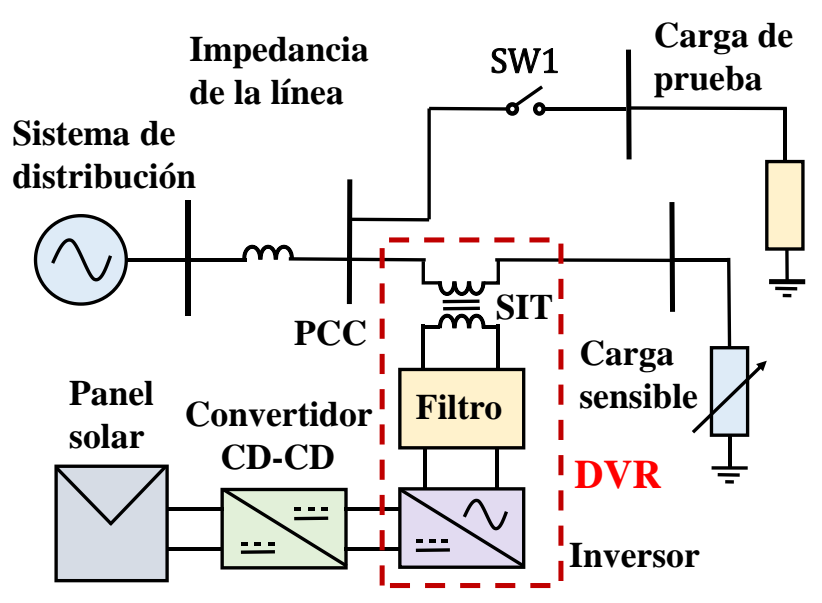

Figure 1 Block diagram of the DVR structure Source: Own Elaboration

The operating principle of the DVR is to inject the compensation voltage $V_{\text {iny }}$ by means of a three-phase injection transformer (SIT), together with the supply voltage $V_{s}$ in order to mitigate voltage dips on the load side $V_{\text {carga }}($ Figure 2$)$.

At all times the control algorithm compares the voltage at the load with a reference voltage and the difference between these two signals is considered the compensation voltage signal $V_{\text {com }}$, which is directly proportional to the voltage to be injected by the inverter $V_{\text {iny }}$. $V_{\text {com }}$ is a digital input signal for pulse width modulation (PWM) to control the voltage source converter (inverter). The inverter converts the $\mathrm{DC}$ power from the solar panels to AC voltage for injection when a load disturbance occurs. And the DC-DC converter controls and regulates the required $\mathrm{DC}$ voltage. 


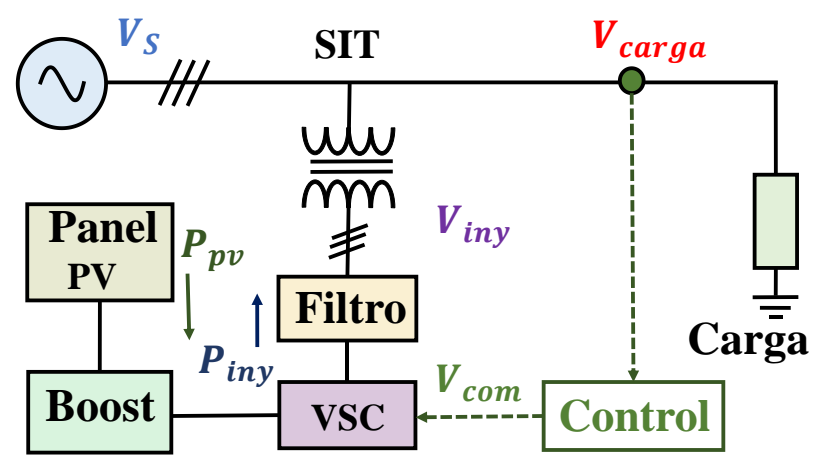

Figure 2 Simplified DVR schematic Source: Own Elaboration

\section{DVR Control}

One of the requirements of the DVR is that it must operate in real time, that is, the compensation process must be executed immediately after the fault occurs without time delay, the speed of response is an essential feature in this device. The variables required for the control are the voltage measured directly at the load, and as output will be obtained the SPWM pulses going to the inverter. In this article the control algorithm implemented is based on the DQ transform (dq0- directquadrature-zero), this is a very useful mathematical transform used to simplify the analysis of three-phase circuits. The $d q 0$ transform is called Park transform and this is complementary with the Clark or $\alpha \beta$ transform.

\section{Clark and Park transforms.}

The Clark transform or $\alpha \beta$ transform offers the advantage of reducing the order of the space in which three-phase signals are represented from 3 to 2 . In matrix form one has:

$$
\left[\begin{array}{l}
V_{\alpha} \\
V_{\beta}
\end{array}\right]=\sqrt{\frac{2}{3}}\left[\begin{array}{ccc}
1 & -0.5 & -0.5 \\
0 & -0.866 & 0.866
\end{array}\right]\left[\begin{array}{l}
V_{a} \\
V_{b} \\
V_{c}
\end{array}\right]
$$

The contants in (1) are obtained from the trigonometric functions of the angles of the different phases, i.e:

$$
\begin{aligned}
& \sin (60)=\frac{\sqrt{3}}{2} \approx 0.8660 \\
& \cos (60)=\frac{1}{2}=0.5
\end{aligned}
$$

It can also be represented in the form of blocks (1) as shown in Figure 3.

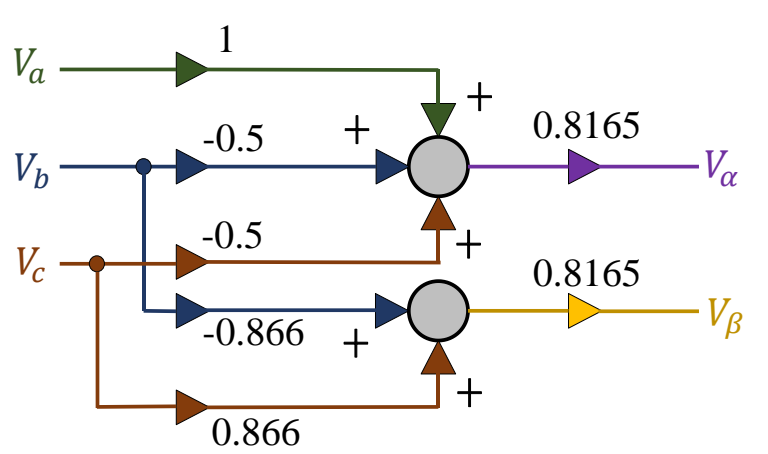

Figure 3 Transformation block abc- $\alpha \beta$ Source: Own Elaboration

When applying a feedback control it is highly desirable to do so with signals that do not vary with time, however, the components in $\alpha \beta$ vary sinusoidally. For this, the Park transform is used, which has as input the vector integrated in the reference frame $\alpha \beta$, and as output a vector in the reference frame $d q$, whose components are constant in time. The Park transform can be expressed as:

$\left[\begin{array}{l}V_{d} \\ V_{q}\end{array}\right]=\left[\begin{array}{cc}\cos \theta & \sin \theta \\ -\sin \theta & \cos \theta\end{array}\right]\left[\begin{array}{l}V_{\alpha} \\ V_{\beta}\end{array}\right]$

Generally in practical applications (2) is not used but the inverse Park's transform, in order to inject a signal in phase or quadrature with the signal taken as reference. The finite inverse transform dq is expressed as:

$$
\left[\begin{array}{l}
V_{\alpha} \\
V_{\beta}
\end{array}\right]=\left[\begin{array}{cc}
\cos \theta & -\sin \theta \\
\sin \theta & \cos \theta
\end{array}\right]\left[\begin{array}{l}
V_{d} \\
V_{q}
\end{array}\right]
$$

The block representation of (3) is shown in Figure 4.

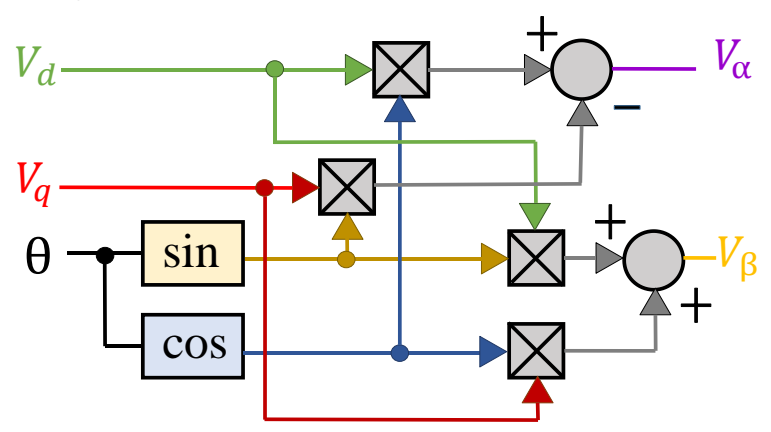

Figure 4 Inverse transformation block dq Source: Own Elaboration 


\section{Schematic of the proposed controller}

For three-phase systems it is also required to find the value of the angle $\theta$ of the reference vector to be evaluated in the inverse transform. For this purpose, a phase-locked loop "PLL" is used, this is responsible for measuring the angle of the reference vector against the $\alpha$-axis, and thereby evaluating the inverse Park's transform. Figure 5 shows the control scheme used.

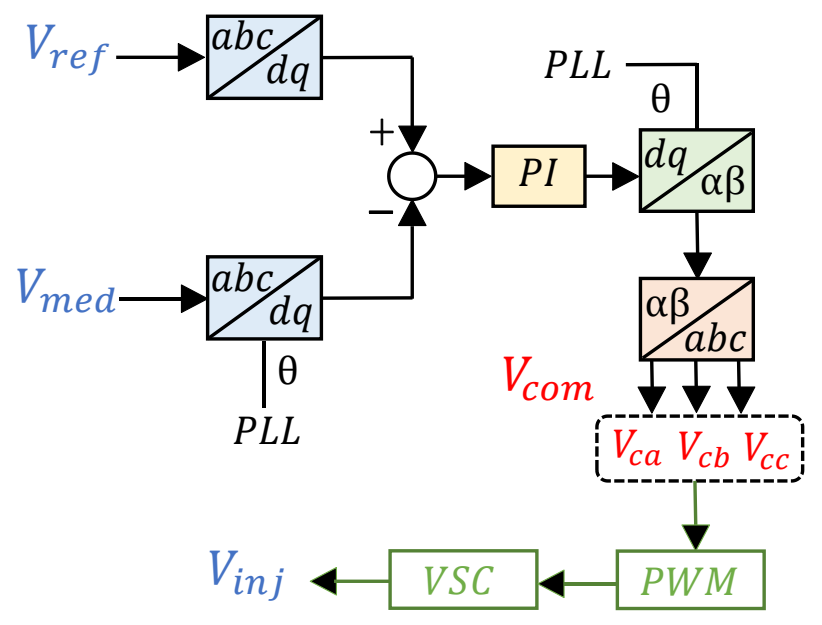

Figure 5 Proposed control scheme Source: Own Elaboration

The way the control circuit operates as shown in Figure 5 is to first measure the threephase voltage at the load $V_{\text {med }}$. Then these values are transformed to a reference frame dq and these in turn compared with a reference value $V_{r e f}$ which is the desired value of the voltage at the load. The difference or error enters a PI regulator, this controller regulates the compensation voltage $V_{\text {com }}$ which is transformed back to an $a b c$ system, and the resulting voltage signals are directly sent to the switching system of the PWM inverter switches.

The SPWM signals are used for switching the semiconductor devices that make up the voltage inverter, and this generates the voltage to be injected in series with the distribution line $V_{\text {iny }}$ through the injection transformers.

\section{Simulation Results}

In order to understand the performance of the DVR under voltage dips, a low voltage distribution network is simulated in MATLAB/SIMULINK (Figure 6).
This DVR uses a three-phase injection transformer consisting of three single-phase transformers in primary-star and secondary series connection, whose transformation ratio is $1: 1$.

In addition, a three-phase PWM voltage inverter to which an LCR filter is connected to its output to eliminate the high frequency components in the inverter output voltage. Table 1 specifies the overall system parameters.

It is worth mentioning that this article considers the photovoltaic modules operating in ideal mode, i.e., they operate with a constant temperature and irradiance of $25^{\circ} \mathrm{C}$ and 1000 $\mathrm{W} / \mathrm{m}^{2}$, so they will always deliver the maximum power according to the specifications.

\begin{tabular}{|l|c|l|}
\hline Parameter & Symbol & Value \\
\hline System voltage & $V_{S}$ & $220 \mathrm{~V}$ \\
\hline Frequency & $f$ & $60 \mathrm{~Hz}$ \\
\hline Active load power & $P_{\text {carga }}$ & $1 \mathrm{~kW}$ \\
\hline Power factor & $f d p$ & $0.8(-)$ \\
\hline Load resistance & $R_{\text {carga }}$ & $30.97 \Omega$ \\
\hline Load inductance & $L_{\text {carga }}$ & $61.6 \mathrm{mH}$ \\
\hline Filter resistance & $R_{\text {filtro }}$ & $1000 \Omega$ \\
\hline Filter inductance & $L_{\text {filtro }}$ & $3.3 \mathrm{mH}$ \\
\hline Filter capacitance & $C_{\text {filtro }}$ & $4.7 \mu \mathrm{F}$ \\
\hline PV panel power & $P_{p v}$ & $80 \mathrm{~W}$ \\
\hline Number of panels in series & $N_{s}$ & 3 \\
\hline Number of panels in parallel & $N_{p}$ & 1 \\
\hline Comprehensive income & $K_{i}$ & 5721 \\
\hline Proportional gain & $K_{p}$ & -0.004 \\
\hline
\end{tabular}

Table 1 DVR parameters Source: Own Elaboration

Figure $7 \mathrm{a}$ shows a three-phase symmetrical voltage dip of $0.7 \mathrm{p}$. u ranging from 50 to 116 milliseconds at the system voltage source.

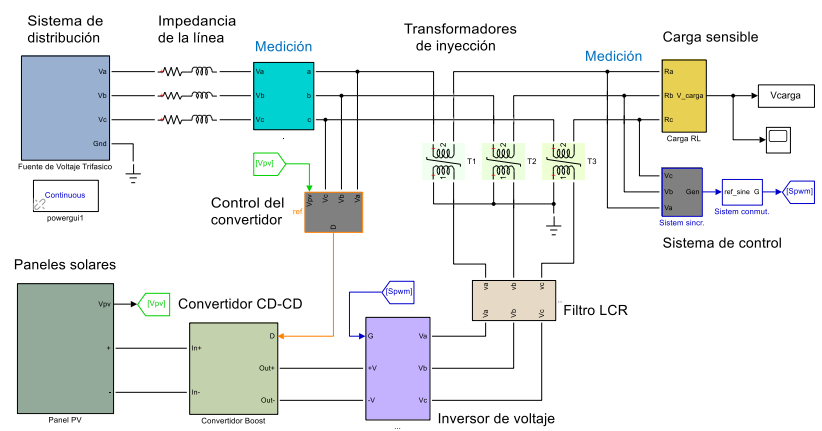

Figure 6 DVR implemented in MATLAB/Simulink 


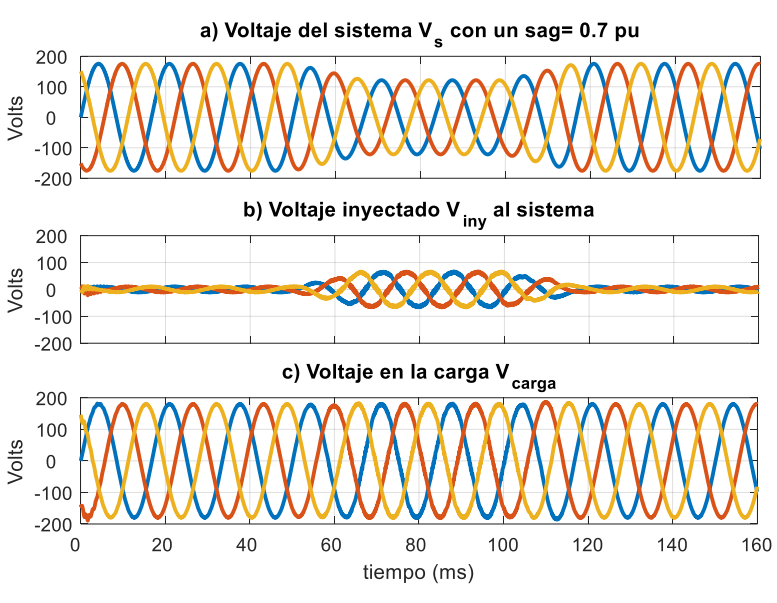

Figure 7 Voltages at a voltage dip Source: MATLAB/Simulink

The compensation voltage provided by the injection transformers, and generated by the control system is shown in Figure $7 \mathrm{~b}$, and the voltage at the compensated load is observed in Figure 7c.

In order to support deep voltage dips, the solar panel system is sized with a series-parallel configuration; 3 panels in series and 1 in parallel, all $80 \mathrm{~W}$ pico modules. Figure 8 shows the power delivered by the array of panels and the power delivered by the Boost converter, note that these have close values because the DC-DC converter operates in an ideal way.
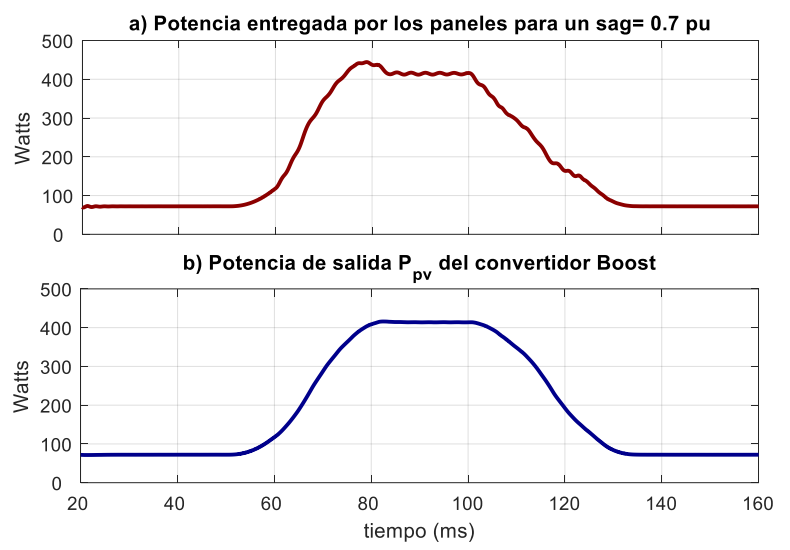

Figure 8 Instantaneous power delivered by the panels Source: MATLAB/Simulink

The instantaneous active power at the occurrence of the voltage dip, and the one afterwards with the compensation at the load is visualized in Figure 9.
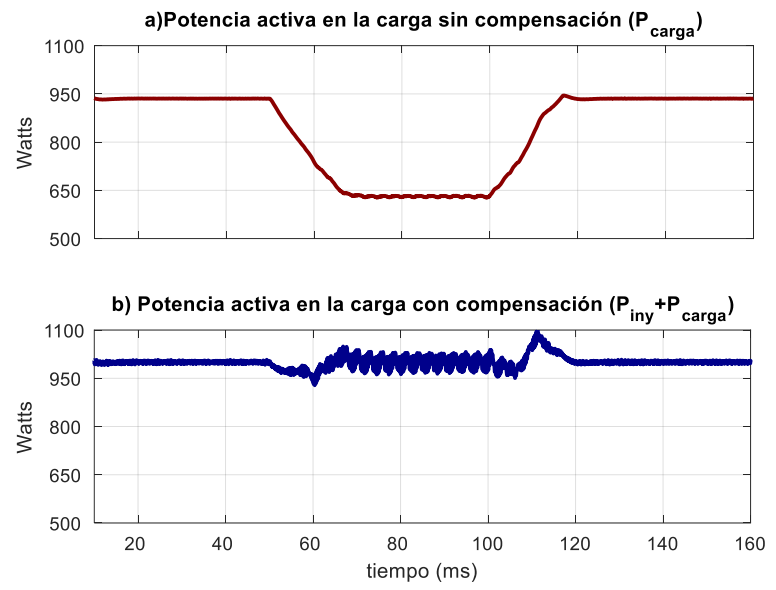

Figure 9 Active power in the load. Source: MATLAB/Simulink

The voltage at the terminals of the panel array $\left(V_{p v}\right)$ can be seen in Figure 10 and it is observed that the voltage is practically constant, while the voltage at the output of the boost converter or Boost $\left(V_{\text {boost }}\right)$ increases when the symmetrical voltage gap occurs in the system, this DC-DC converter raises the voltage from the panels to levels required for compensation through the control system of the converter, varying the duty cycle (D) depending on the voltage required to inject the inverter to the system. The duty cycle variation is shown in Figure 11. Before and after the voltage dip occurs, the boost converter maintains a constant duty cycle in order to operate in continuous conduction mode.

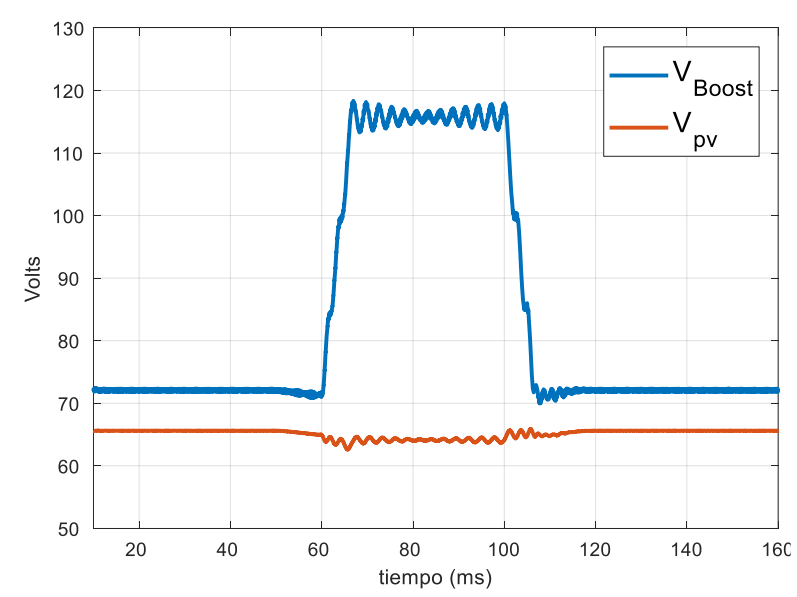

Figure 10 Panel voltage and Boost converter output voltage

Source: MATLAB/Simulink 


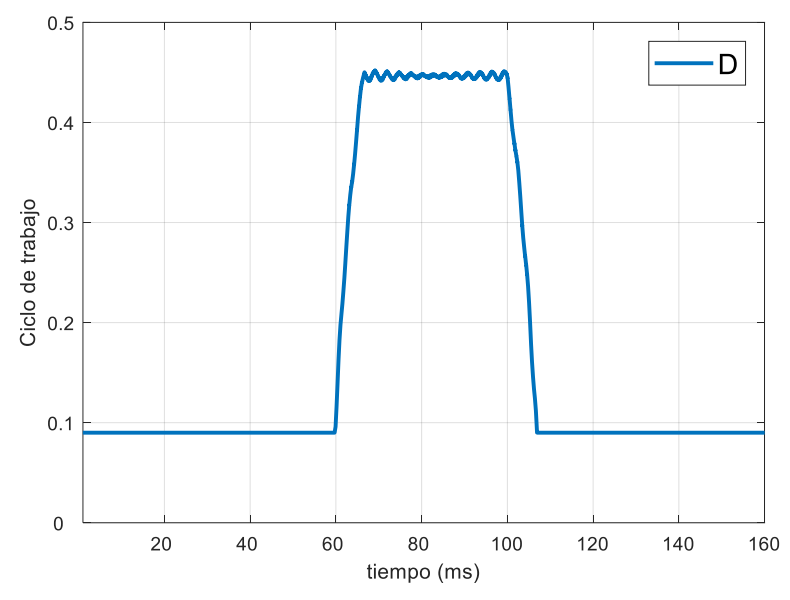

Figure 11 Duty cycle applied to the Boost Converter Source: MATLAB/Simulink

\section{Acknowledgments}

The authors would like to thank the Tecnológico Nacional de México campus Ciudad Madero and CONACYT with grant number (758746) for the support for the development of this project.

\section{Conclusions}

In this paper, a topology with solar panels was presented to provide support to the DVR against symmetrical voltage dips and to achieve greater compensation depth by injecting active power. Simulation results performed in MATLAB/SIMULINK demonstrate the effectiveness of the proposed structure against this type of disturbances. It is worth mentioning that for future work an energy storage system could be added to improve the system, such as batteries and/or a capacitor bank, the latter to have the possibility of injecting reactive power.

\section{References}

Nguyen Van Minh, Bach Quoc Khanh y Pham Viet Phuong, "Comparative simulation results of DVR and D-STATCOM to improve voltage quality in distributed power system," 2017 International Conference on System Science and Engineering (ICSSE), 2017, pp. 196-199.

D. Szabó, R. Bodnár, M. Regul'a y J. Altus, "Designing and modelling of a DVR in Matlab," Proceedings of the 2014 15th International Scientific Conference on Electric Power Engineering (EPE), 2014, pp. 229-233.

P. M. Garcia-Vite, F. Mancilla-David y J. M. Ramirez, "Dynamic modeling and control of an AC-link dynamic voltage restorer," 2011 IEEE International Symposium on Industrial Electronics, 2011, pp. 1615-1620.
Julio C. Rosas-Caro, Juan M. Ramírez, Pedro M. Vite García, Antonio Valderrábano y Nojja V.Vanegas Méndez. "Control de acondicionadores de potencia y dispositivos FACTS".

M. N. Tandjaoui, C. Benachaiba, O. Abdelkhalek, M. L. Doumbia e Y. Mouloudi, "Sensitive loads voltage improvement using Dynamic Voltage Restorer," Proceedings of the 2011 International Conference on Electrical Engineering and Informatics, 2011, pp. 1-5.

R. A. Kantaria, S. K. Joshi y K. R. Siddhapura, "A novel technique for mitigation of voltage sag/swell by Dynamic Voltage Restorer (DVR)," 2010 IEEE International Conference on Electro/Information Technology, 2010, pp. 1-4. 